\title{
Activating mutation (V617F) in the tyrosine kinase JAK2 is absent in locally-confined or castration-resistant prostate cancer
}

\author{
Lei Gu ${ }^{\text {a }}$, Xian-Hua Zhu ${ }^{\text {b }}$, Tapio Visakorpi ${ }^{\mathrm{c}}$, Kalle Alanen ${ }^{\mathrm{d}}$, Tuomas Mirtti ${ }^{\mathrm{d}}$, \\ Tina Bocker Edmonston ${ }^{b}$ and Marja T. Nevalainen ${ }^{\text {a,e,f,* }}$ \\ ${ }^{a}$ Department of Cancer Biology, Kimmel Cancer Center, Thomas Jefferson University, Philadelphia, PA, USA \\ ${ }^{\mathrm{b}}$ Department of Pathology, Anatomy and Cell Biology, Thomas Jefferson University, Philadelphia, PA, USA \\ ${ }^{\mathrm{c}}$ Institute of Medical Technology, University of Tampere and Tampere University Hospital, Tampere, Finland \\ ${ }^{\mathrm{d}}$ Department of Pathology, Institute of Biomedicine, University of Turku, Turku, Finland \\ e Department of Urology, Thomas Jefferson University, Philadelphia, PA, USA \\ ${ }^{\mathrm{f}}$ Department of Medical Oncology, Thomas Jefferson University, Philadelphia, PA, USA
}

\begin{abstract}
Background: Transcription factor Stat5a/b is highly critical for the viability of human prostate cancer cells in vitro and for prostate tumor growth in vivo. Stat5 is constitutively active in clinical prostate cancers but not in the normal human prostate epithelium. Moreover, Stat5a/b activation in prostate cancer is associated with high histological grade of prostate cancer. However, the molecular mechanisms underlying constitutive activation of Stat5a/b in prostate cancer are unclear. The receptorassociated tyrosine kinase Jak2 is a known key activator of Stat5a/b in prostate cancer cells in response to ligand stimulation. Recently, a single gain-of-function point mutation of $J A K 2$ was described in myeloproliferative diseases leading to constitutive Jak2 kinase activity, subsequent Stat5a/b activation and involvement of V617F Jak2 in the pathogenesis of myeloproliferative disorders.

Materials and methods: We determined whether JAK2 undergoes the V617F activating mutation during clinical progression of human prostate cancer using a highly sensitive assay (amplification refractory mutation system) and a unique material of fresh specimens from organ-confined or castration-resistant prostate cancers.

Results: The JAK2 V617F mutation was not found in any of the normal or malignant prostate samples analyzed in this study.

Conclusions: Future work should focus on determining the molecular mechanisms other than V617F mutation of Jak2 resulting in continuous Stat5 activation in clinical prostate cancers.
\end{abstract}

Keywords: JAK2 V617 mutation, prostate cancer

\section{Introduction}

Transcription factor Stat $5 \mathrm{a} / \mathrm{b}$ is highly critical for the viability and growth of prostate cancer. Inhibition of Stat5 induces rapid apoptotic death of human prostate cancer cells [1-3], blocks human prostate cancer xenograft tumor growth in nude mice [3], and inhibits progression of prostate cancer in the TRAMP

\footnotetext{
*Corresponding author: Marja T. Nevalainen, MD, PhD, Department of Cancer Biology, Kimmel Cancer Center, Thomas Jefferson University, 233 S. 10th Street, BLSB 309, Philadelphia, PA 19107, USA. Tel.: +1 215503 9250; Fax: +1 215503 924; E-mail: marja.nevalainen@jefferson.edu or M_Nevalainen@mail. jci.tju.edu.
}

mouse prostate cancer model [5]. Moreover, Stat5a/b is constitutively active in human prostate cancer but not in normal prostate epithelium [1], and activation of $\mathrm{Stat} 5 \mathrm{a} / \mathrm{b}$ in prostate cancer epithelium is associated with lesions of high histological grades [7,8]. In primary organ-confined prostate cancer, activation of Stat5a/b predicts early disease recurrence [8]. In addition, Stat $5 \mathrm{a} / \mathrm{b}$ is activated in the majority of castrationresistant recurrent human prostate cancers [15], and active Stat5a/b synergizes with androgen receptor (AR) suggesting an involvement of Stat $5 \mathrm{a} / \mathrm{b}$ in the promotion of castration-resistant growth of prostate cancer [15]. The molecular mechanisms underlying constitutive activation of Stat $5 \mathrm{a} / \mathrm{b}$ in prostate cancer are unclear. The receptor-associated tyrosine kinase Jak2 is a known 
key activator of $S t a t 5 a / b$ in prostate cancer cells in response to ligand stimulation [7]. Recently, a single gain-of-function point mutation of $J A K 2$ was described in myeloproliferative diseases leading to constitutive Jak2 kinase activity, subsequent Stat5a/b activation and involvement of $\mathrm{V} 617 \mathrm{~F}$ Jak2 in the pathogenesis of myeloproliferative disorders [4,6,14]. This acquired somatic V617F JAK2 mutation is located at amino acid position 617 within the $\mathrm{JH} 2$ autoinhibitory domain of Jak2 resulting in valine substitution to phenylalanine. Little is known about the direct involvement of Jak2 in prostate carcinogenesis. Specifically, it is not known whether Jak2 V617F is able to transform normal prostate epithelium. While constitutive Stat5a/b activation suggests hyperactivity of Jak2 in prostate cancer cells, no studies exist at present on Jak2 activation state in clinical prostate cancers. In this work, we determined whether $J A K 2$ undergoes the V617F activating mutation during progression of clinical human prostate cancer.

\section{Materials and methods}

\subsection{Study subjects}

Normal and malignant freshly frozen prostate tissues $(n=78)$ were obtained from the University of Turku (Turku, Finland): 19 benign prostate hy- perplasias (BPH), 3 prostate intraepithelial neoplasias (PIN) and 57 primary organ-confined prostate cancers of different histological grades (Table 1). DNA was extracted using QIAamp DNA Micro kit (Qiagen Inc., Valencia, CA) according to the manufacturer's instructions.

Freshly frozen samples of 14 castration-resistant prostate cancers (Tampere University Hospital, Tampere, Finland) were from patients who had experienced a local progression of the disease during hormonal therapy (Table 1). The therapy modalities were: orchiectomy (4 cases), LHRH (luteinizing hormonereleasing hormone) analog (3 cases), estrogen ( 2 cases), orchiectomy and estrogen (2 cases), combined androgen blockade (CAB) (2 cases), and unknown (1 case). The mean time from the onset of the androgen ablation to the progression was 40 months (range: 15-68 months). DNA was amplified with GenomiPhi ${ }^{\mathrm{TM}}$ DNA amplification kit (Amersham, GE Healthcare, UK) according to the manufacturer's instructions.

The use of de-identified archival tissue specimens in research was approved by the Ethics Committee of the Turku University Hospital, the Ethics Committee of the Tampere University Hospital and by the Thomas Jefferson University Institutional Review Board. All of the specimens were histologically examined for the presence of cancer ( $>60 \%$ of cells) using hematoxylineosin-stained slides (Table 1).

Table 1

Prostate cancer specimens

\begin{tabular}{|c|c|c|}
\hline Prostate samples & No. of patients & $\%$ \\
\hline Prostate intraepithelial neoplasia (PIN) & 3 & 100 \\
\hline Benign prostate hyperplasia (BPH) & 19 & 100 \\
\hline Organ-confined primary prostate cancer & 56 & 100 \\
\hline Gleason grade 2 & 4 & 7 \\
\hline Gleason grade 3 & 13 & 23 \\
\hline Gleason grade 4 & 27 & 48 \\
\hline Gleason grade 5 & 8 & 14 \\
\hline Gleason grade 6 & 2 & 4 \\
\hline Gleason grade 7 & 2 & 4 \\
\hline Castration-resistant prostate cancer & 14 & 100 \\
\hline \multicolumn{3}{|l|}{ Treatment } \\
\hline Orchiectomy & 4 & 29 \\
\hline Luteinizing hormone-releasing hormone (LHRH) & 3 & 21 \\
\hline Estrogen & 2 & 14 \\
\hline Orchiectomy and estrogen & 2 & 14 \\
\hline Combined androgen blockage (CAB) & 2 & 14 \\
\hline Unknown & 1 & 8 \\
\hline Total & 93 & \\
\hline
\end{tabular}




\subsection{JAK2 V617F mutation analysis}

DNA (240 ng) of each sample was amplified in a $50 \mu \mathrm{l}$ reaction using an amplification refractory mutation system (ARMS) [9,11] assay. Each reaction contained $400 \mathrm{ng}$ of the JAK2 forward primer (JAK2FOR) (5'-tgaagcagcaagtatgatgag, TIB Molbiol, Adelphia, NJ), $400 \mathrm{ng}$ of the JAK2 mutation specific forward primer (JAK2-MFOR) (5-gcatttggttttaaattatggagt atatt, TIB Molbiol, Adelphia, NJ), which was nested with respect to $400 \mathrm{ng}$ of the $J A K 2$ forward primer and $400 \mathrm{ng}$ of the $J A K 2$ reverse primer (JAK2-REV) (5'-6FAM-tacactgacacctagctgtga, TIB Molbiol, Adelphia, NJ) [9]. In addition, each reaction contained $200 \mu \mathrm{M}$ of each deoxynucleotide triphosphate (Roche, Indianapolis, IN), $1 \times$ Gene Amp PCR buffer with $\mathrm{MgCl}_{2}$ and $1 \mathrm{U}$ of AmpliTaq Gold DNA Polymerase (Applied Biosystems, Foster City, CA). The 174 bp fragment of the JAK2 gene that was amplified with the JAK2-FOR primer and the JAK2-REV primers, served as an internal amplification control. This re-

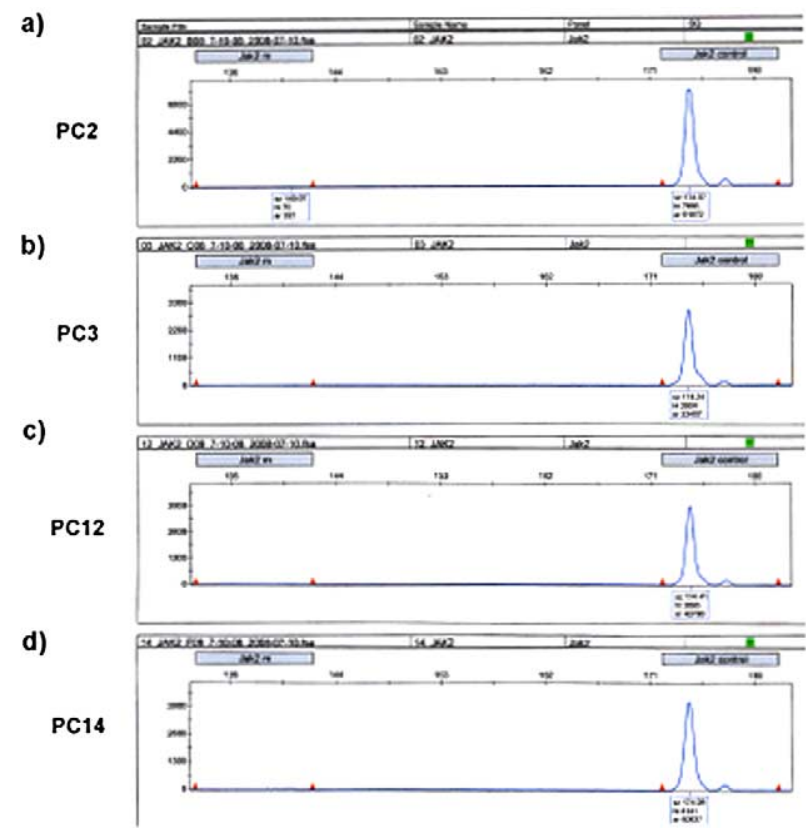

action was multiplexed with the amplification of the mutant sequence - if present - which rendered a 140 bp PCR amplicon using the mutation-specific JAK2-MFOR primer together with the JAK2-REV primer.

The cycling conditions for the prostate cancer DNA were $95^{\circ} \mathrm{C}$ for $10 \mathrm{~min}$ to activate the DNA polymerase, and 29 cycles of $95^{\circ} \mathrm{C}$ for $15 \mathrm{~s}, 58^{\circ} \mathrm{C}$ for $20 \mathrm{~s}$ and $73^{\circ} \mathrm{C}$ for $15 \mathrm{~s}$ on the GeneAmp PCR System 9700 (Applied Biosystems, Foster City, CA). The following controls were included: negative, $1 \%$ positive, $2 \%$ positive and $100 \%$ positive (Invivoscribe, San Diego, CA) as well as a no template control. For samples with small amounts of DNA, the cycle number was increased to 34 cycles. Each PCR product $(1 \mu \mathrm{l})$ was mixed with $12 \mu \mathrm{l}$ of deionized formamide (Applied Biosystems, Foster City, CA) and $0.5 \mu \mathrm{l}$ of GeneScan ROX-500 (Applied Biosystems, Foster City, CA), heat-denatured and loaded on the ABI 3100 Avant Genetic Analyzer (Applied Biosystems, Foster City, CA) for a 6 second injection using POP4 polymer (Applied Biosystems, Foster City, CA).

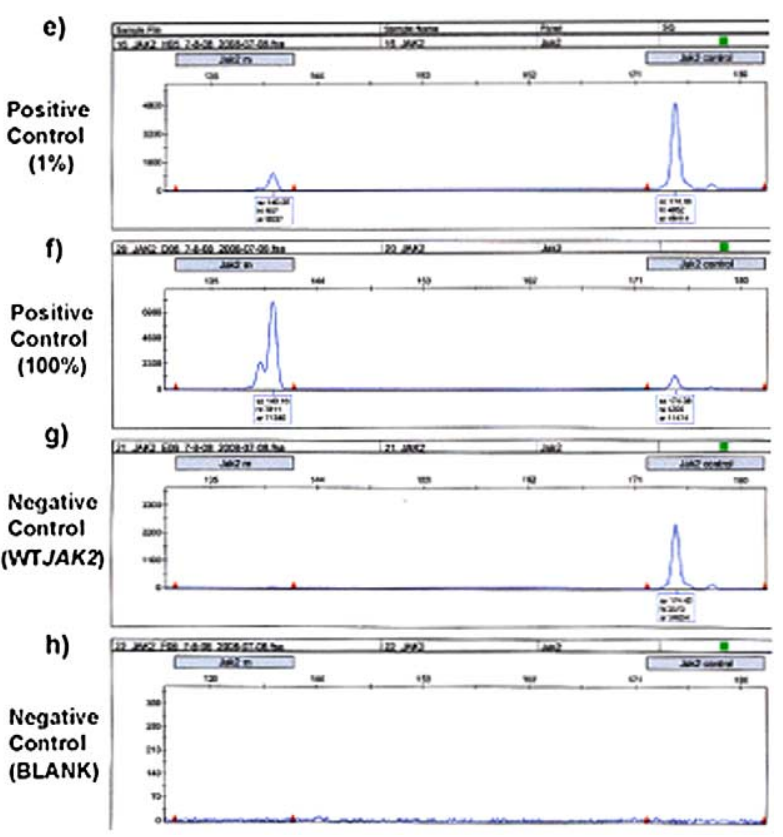

Fig. 1. Analysis of JAK2 V617F mutation using an amplification refractory mutation system (ARMS) assay in benign prostate hyperplasias, prostate intraepithelial neoplasias, primary prostate cancers of different histological grades and castration-resistant prostate cancers. Selected cases of prostate cancers (PC2, PC3, PC12 and PC14) are presented showing amplification of the 174 bp internal control peak only (a-d). The positive controls were the following: (1) Template containing 1\% of DNA with the JAK2 V617F point mutation with $99 \%$ of DNA containing the wild type $J A K 2$ sequence (1\%) (e) and (2) $100 \%$ of DNA containing the point mutation (100\%) (f). The positive controls show both of the peaks which represent the mutation at $140 \mathrm{bp}$ and the $174 \mathrm{bp}$ internal control peak. The results for 5\%, 10\% and 30\% positive controls are not shown. DNA with the wild type (WT) JAK2 sequence showing the $174 \mathrm{bp}$ internal control peak only was used as a negative control (g). An additional negative control which did not contain any template (BLANK) shows no amplification (f). 


\section{Results and discussion}

Using a highly specific amplification refractory mutation system (ARMS) assay, we evaluated 19 benign prostate hyperplasias (BPH), 3 prostate intraepithelial neoplasia (PIN) lesions, 56 organ-confined primary prostate cancers and 14 castration-resistant prostate cancers (Table 1) for the activating V617F mutation in the tyrosine kinase Jak2. None of the benign or malignant prostate lesions possessed the $J A K 2 \mathrm{~V} 617 \mathrm{~F}$ mutation. Since each cancer sample contained more than $60 \%$ of tumor cells and since the sensitivity of the assay is $1 \%$, heterozygous mutation would have also been detected in our analysis. Of the 93 prostate samples analyzed (Table 1), representative cases of hormone-refractory prostate cancers are presented in Fig. 1(a-d). At the same time, the internal and external controls showed the expected amplicons (Fig. 1, e, f). While the number of cases analyzed is limited, the results of this work suggest that JAK2 gene does not undergo the V617F somatic mutation in primary or castration-resistant prostate cancers, BPHs, or PIN lesions implicating other molecular mechanisms responsible for constitutive activation of $S t a t 5 a / b$ in prostate cancer. These mechanisms may include deactivated phosphatases, deregulated SOCS proteins [13], abnormal assembly of the receptor complexes and involvement of other peptide hormone receptors in the activation of Jak2 [10,12]. Based on the results of this study, future work should focus on determining the molecular mechanisms other than V617F mutation of Jak2 resulting in continuous Stat5 activation in clinical prostate cancers.

\section{Conflict of interest}

No potential conflicts of interest were disclosed.

\section{References}

[1] T.J. Ahonen, J. Xie, M.J. LeBaron, J. Zhu, M. Nurmi, K. Alanen, H. Rui and M.T. Nevalainen, Inhibition of transcription factor Stat5 induces cell death of human prostate cancer cells, J. Biol. Chem. 278 (2003), 27287-27292.

[2] A. Dagvadorj, S. Collins, J.B. Jomain, J. Abdulghani, J. Karras, T. Zellweger, H. Li, M. Nurmi, K. Alanen, T. Mirtti, T. Visakorpi, L. Bubendorf, V. Goffin and M.T. Nevalainen, Autocrine prolactin promotes prostate cancer cell growth via Janus kinase-2-signal transducer and activator of transcription5a/b signaling pathway, Endocrinology 148 (2007), 3089_ 3101 .
[3] A. Dagvadorj, R.A. Kirken, B. Leiby, J. Karras and M.T. Nevalainen, Transcription factor signal transducer and activator of transcription 5 promotes growth of human prostate cancer cells in vivo, Clin. Cancer Res. 14 (2008), 1317-1324.

[4] C. James, V. Ugo, J.P. Le Couedic, J. Staerk, F. Delhommeau, C. Lacout, L. Garcon, H. Raslova, R. Berger, A. BennaceurGriscelli, J.L. Villeval, S.N. Constantinescu, N. Casadevall and W. Vainchenker, A unique clonal JAK2 mutation leading to constitutive signalling causes polycythaemia vera, Nature 434 (2005), 1144-1148.

[5] A.V. Kazansky, D.M. Spencer and N.M. Greenberg, Activation of signal transducer and activator of transcription 5 is required for progression of autochthonous prostate cancer: evidence from the transgenic adenocarcinoma of the mouse prostate system, Cancer Res. 63 (2003), 8757-8762.

[6] R. Kralovics, F. Passamonti, A.S. Buser, S.S. Teo, R. Tiedt, J.R. Passweg, A. Tichelli, M. Cazzola and R.C. Skoda, A gainof-function mutation of JAK2 in myeloproliferative disorders, N. Engl. J. Med. 352 (2005), 1779-1790.

[7] H. Li, T.J. Ahonen, K. Alanen, J. Xie, M.J. LeBaron, T.G. Pretlow, E.L. Ealley, Y. Zhang, M. Nurmi, B. Singh, P.M. Martikainen and M.T. Nevalainen, Activation of signal transducer and activator of transcription 5 in human prostate cancer is associated with high histological grade, Cancer Res. 64 (2004), 4774-4782.

[8] H. Li, Y. Zhang, A. Glass, T. Zellweger, E. Gehan, L. Bubendorf, E.P. Gelmann and M.T. Nevalainen, Activation of signal transducer and activator of transcription-5 in prostate cancer predicts early recurrence, Clin. Cancer Res. 11 (2005), 5863 5868.

[9] R. McClure, M. Mai and T. Lasho, Validation of two clinically useful assays for evaluation of JAK2 V617F mutation in chronic myeloproliferative disorders, Leukemia 20 (2006), 168-171.

[10] R. Montironi, L. Cheng, R. Mazzucchelli, D. Morichetti, D. Stramazzotti, A. Santinelli, G. Moroncini, A.B. Galosi, G. Muzzonigro, G. Comeri, J. Lovisolo, S. Cosciani-Cunico and A.V. Bono, Immunohistochemical detection and localization of somatostatin receptor subtypes in prostate tissue from patients with bladder outlet obstruction, Cell. Oncol. 30 (2008), 473-482.

[11] C.R. Newton, A. Graham, L.E. Heptinstall, S.J. Powell, C. Summers, N. Kalsheker, J.C. Smith and A.F. Markham, Analysis of any point mutation in DNA. The amplification refractory mutation system (ARMS), Nucleic Acids Res. 17 (1989), 2503-2516.

[12] M.E. Pretorius, H. Waehre, V.M. Abeler, B. Davidson, L. Vlatkovic, R.A. Lothe, K.E. Giercksky and H.E. Danielsen, Large scale genomic instability as an additive prognostic marker in early prostate cancer, Cell. Oncol. 31 (2009), 251259.

[13] M. Puhr, F.R. Santer, H. Neuwirt, G. Marcias, A. Hobisch and Z. Culig, SOCS-3 antagonises the proliferative and migratory effects of fibroblast growth factor- 2 in prostate cancer by inhibition of p44/p42 MAPK signalling, Endocr. Relat. Cancer 17, 525-538.

[14] L.M. Scott, W. Tong, R.L. Levine, M.A. Scott, P.A. Beer, M.R. Stratton, P.A. Futreal, W.N. Erber, M.F. McMullin, C.N. Harrison, A.J. Warren, D.G. Gilliland, H.F. Lodish and 
A.R. Green, JAK2 exon 12 mutations in polycythemia vera and idiopathic erythrocytosis, N. Engl. J. Med. 356 (2007), 459468.

[15] S.H. Tan, A. Dagvadorj, F. Shen, L. Gu, Z. Liao, J. Abdulghani, Y. Zhang, E.P. Gelmann, T. Zellweger, Z. Culig, T. Visako- rpi, L. Bubendorf, R.A. Kirken, J. Karras and M.T. Nevalainen, Transcription factor Stat5 synergizes with androgen receptor in prostate cancer cells, Cancer Res. 68 (2008), 236-248. 


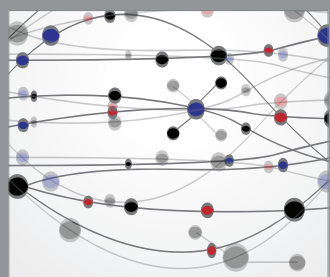

The Scientific World Journal
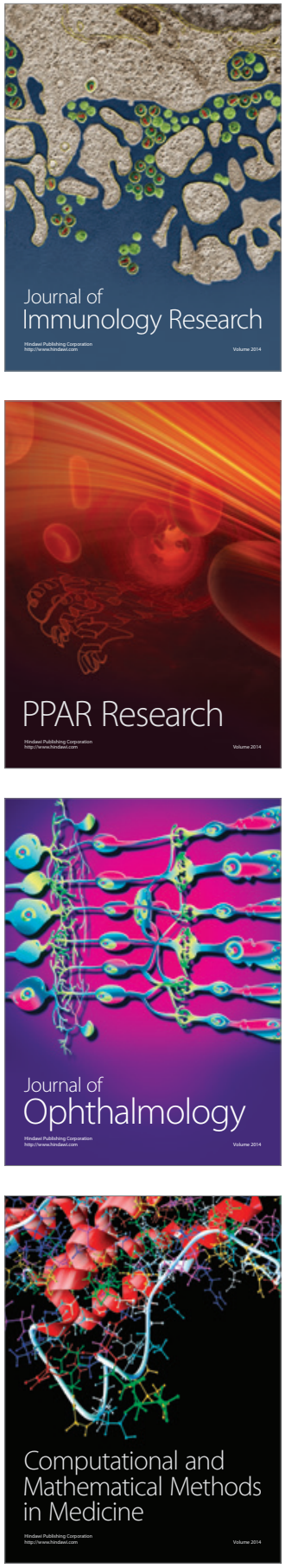

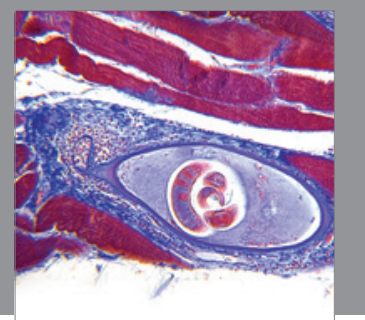

Gastroenterology

Research and Practice
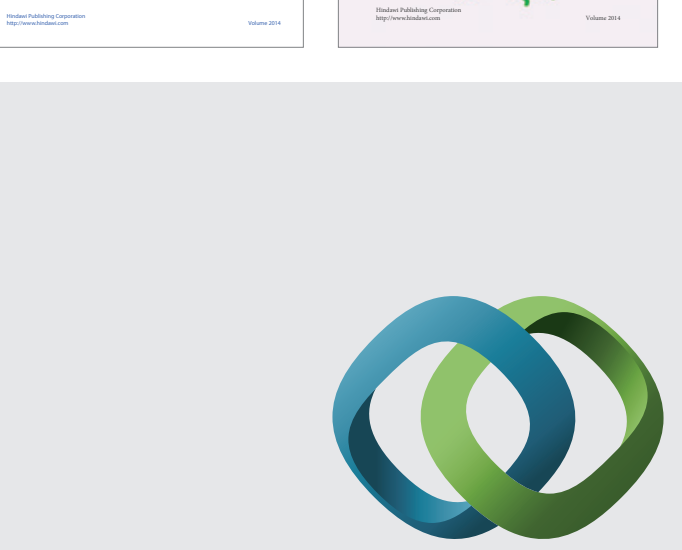

\section{Hindawi}

Submit your manuscripts at

http://www.hindawi.com
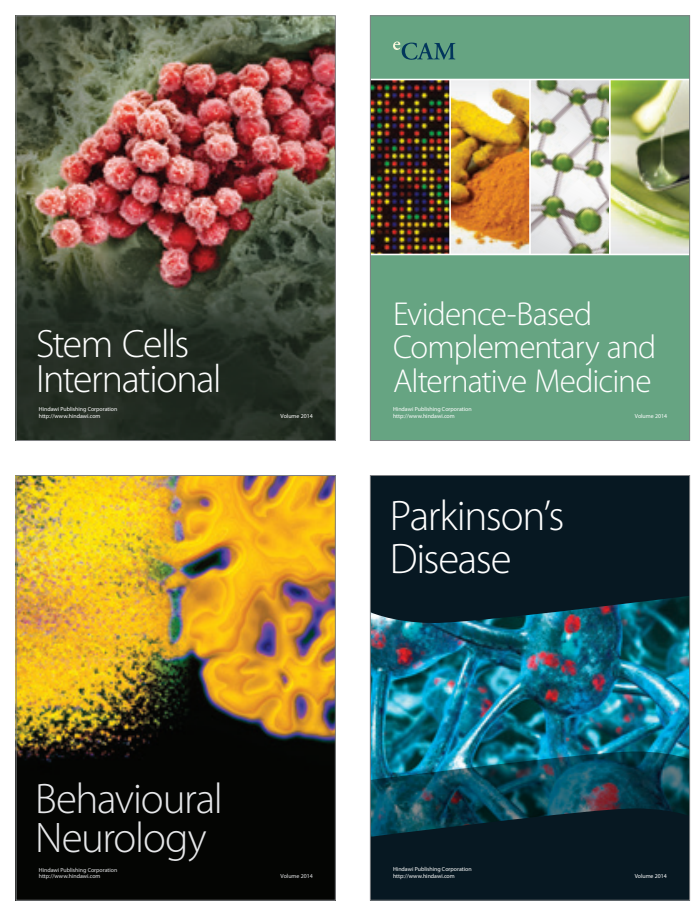

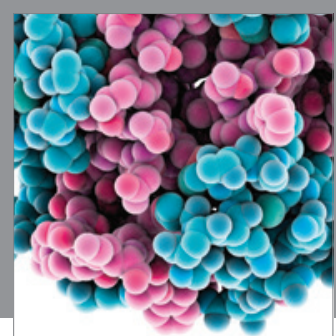

Journal of
Diabetes Research

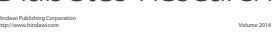

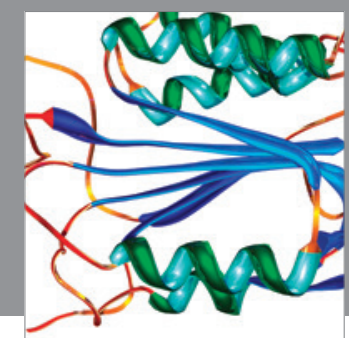

Disease Markers
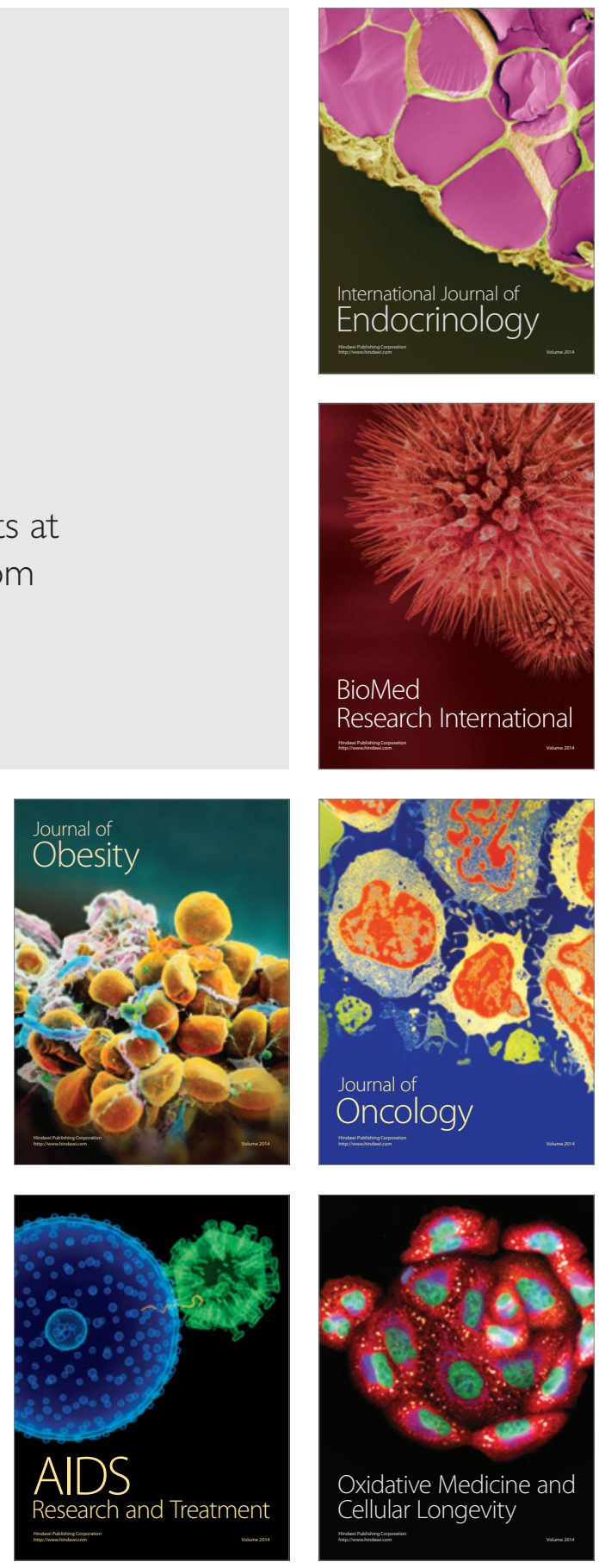